\title{
Loss of BAF250a Expression
}

National Cancer Institute

\section{Source}

National Cancer Institute. Loss of BAF250a Expression. NCI Thesaurus. Code C114559.

Loss of protein expression of the BRG-associated factor 250a (BAF250a). It is caused by mutation of the tumor-suppressor gene ARID1A. It is linked to tumor progression and poor prognosis in various cancers. 